\section{SAT0572 INITIAL STRUCTURAL RESPONSE PREDICTS LONG- TERM SURVIVAL OF KNEE JOINT DISTRACTION AS A TREATMENT FOR KNEE OSTEOARTHRITIS}

M. Jansen ${ }^{1}$, G. Van der Weiden ${ }^{1}$, R. Custers ${ }^{2}$, S. Mastbergen ${ }^{1}$, F. Lafeber ${ }^{1}$. ${ }^{1}$ Rheumatology and Clinical Immunology, ${ }^{2}$ Department of Orthopedics, University Medical Center Utrecht, Utrecht, Netherlands

Background: In relatively young patients with end-stage knee osteoarthritis $(\mathrm{OA})$, total knee arthroplasty (TKA) comes with the risk of revision surgery ${ }^{1}$. Knee joint distraction (KJD) is a joint preserving surgery technique, which has been shown to provide clinical and structural improvement for at least five years ${ }^{2}$ and postpones the need for TKA.

Objectives: To evaluate long-term clinical and structural results and identify characteristics predicting survival of the native knee joint after KJD.

Methods: End-stage tibiofemoral OA patients $(\mathrm{n}=20$; age $<60$ years) indicated for TKA were treated with KJD. WOMAC questionnaires (100 best) and VAS pain scores ( 0 best) were used for clinical evaluation at baseline and every year after treatment, up to 9 years. Minimum and mean joint space width (JSW) and mean bone density of the most affected compartment (MAC) were measured using KIDA software on standardised radiographs (baseline and 1,2,5 and 7 years after treatment). The mean cartilage thickness of the MAC was measured on MRI scans (baseline and 1,2 and 5 years after treatment). Survival after treatment was analysed (failure defined by TKA). Prediction of KJD survival was studied by logistic regression analyses.

Results: Three patients withdrew consent. Survival 9 years after treatment was $48 \%$. Survival percentages differed significantly for gender (women $14 \%$, men $70 \% ; \mathrm{p}=0.035$; figure $1 \mathrm{~A}$ ) and for increase in minimum JSW in the 1 st year ( $<0.5 \mathrm{~mm}$ increase $0 \%,>0.5 \mathrm{~mm}$ increase $72 \%$; $\mathrm{p}=0.002$; figure $1 \mathrm{~B}$ ).

Survivors reported clinical improvement compared to baseline: $\triangle W O M A C+29.9$ points $(95 \% \mathrm{Cl}+16.9$ to $+42.9 ; \mathrm{p}=0.001$; figure $1 \mathrm{C}), \Delta \mathrm{VAS}-46.8 \mathrm{~mm}(95 \% \mathrm{Cl}$ -31.6 to $-61.9 ; p<0.001)$. In addition, a significant increase of the minimum JSW $(+0.62 \mathrm{~mm} ; 95 \% \mathrm{Cl}+0.13$ to $+1.11 ; \mathrm{p}=0.020$; figure $1 \mathrm{D})$ was found after 7 years. No significant changes were found for the mean JSW $(+0.36 \mathrm{~mm} ; 95 \% \mathrm{Cl}-0.85$ to $+1.57 ; p=0.505$ ). In patients whose treatment failed over time, last reported clinical scores were still improved compared to baseline: $\triangle W O M A C+20.5$ points $(95 \% \mathrm{Cl}-1.8$ to $+42.8 ; \mathrm{p}=0.067$; figure $1 \mathrm{C}), \Delta \mathrm{VAS}-25.4 \mathrm{~mm}(95 \% \mathrm{Cl}-3.2$ to $-47.7 ; \mathrm{p}=0.030)$. In contrast, the minimum JSW $(+0.22 \mathrm{~mm} ; 95 \% \mathrm{Cl}-0.15$ to $0.58 ; \mathrm{p}=0.205)$ and mean JSW $(+0.21 \mathrm{~mm} ; 95 \% \mathrm{Cl}-1.08$ to $1.51 ; \mathrm{p}=0.712)$ at the last reported time points were no longer increased.

Gender and minimum JSW increase after 1 year predict survival of the native knee joint after 9 years (OR of 14 and 0.02 ; both $p<0.046$ ). The 1 year bone density decrease and mean cartilage thickness increase had a tendency to be predictive (OR of 1.38 and 0.01 ; both $p<0.090$ ).
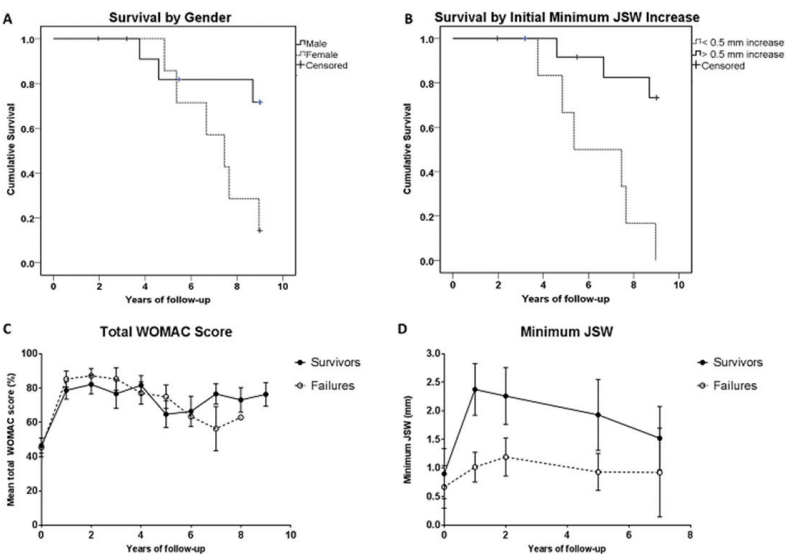

Abstract SAT0572 - Figure 1. Long-term response after treatment with knee joint distraction. (A) Kaplan-Meier survival curves by gender, men $(n=11)$ versus women $(n=9)$, and $(B)$ by increase in minimum joint space width one year after treatment, less than 0.5 $\mathrm{mm}$ increase $(n=7)$ versus more than $0.5 \mathrm{~mm}$ increase $(n=13)$. (C) Total WOMAC score change over nine years and (D) minimum joint space width change over seven years, separated by survivors and patients whose treatment failed within nine years. Mean values \pm SEM are given.

Conclusions: Joint distraction for end-stage knee OA shows long-lasting clinical and structural improvement with a survival of $48 \%$ at 9 years. Clinical scores in patients failing treatment were still improved compared to baseline and cannot fully explain the subsequent TKA surgery. Positive predicting factors for survival of the native knee are male gender and a larger initial increase in minimum JSW (both, $70 \%$ survival at 9 years). Potentially, an initial decrease in bone density and an increase in mean cartilage thickness are predictive as well.

Overall, the initial structural response after KJD appears to be important for longterm success of the treatment.

\section{REFERENCES :}

[1] Kurtz SM, et al. Clin Orthop Relat Res 2009;467(10):2606-12.

[2] J-TAD van der Woude, et al. Cartilage 2017;8(3):263-271.

Disclosure of Interest: None declared

DOI: 10.1136/annrheumdis-2018-eular.3021

\section{SAT0573 PROGRESSION OF PAIN, STIFFNESS, FUNCTION CHANGES, AND ULTRASOUND DETECTED SYNOVITIS AND OSTEOPHYTE FORMATION IN PATIENTS WITH HAND OSTEOARTHRITIS OVER THREE YEARS}

O. Sleglova, O. Ruzickova, K. Pavelka, L. Senolt. Institute of Rheumatology, Prague, Czech Republic

Background: Hand osteoarthritis ( $\mathrm{HOA})$ is a common and frequent cause of pain. $\mathrm{HOA}$ is a heterogeneous group of disorders with two main subsets including non-erosive and erosive disease. Few studies demonstrated inflammatory ultrasound changes and more severe clinical symptoms in patients with erosive compared with non-erosive disease, however the results are inconsistent.

Objectives: The aim of this study was to evaluate progression of pain, stiffness, physical impairment and ultrasound features in patients with erosive and non-erosive HOA in a three years longitudinal study.

Methods: Consecutive patients with symptomatic HOA fulfilling the American College of Rheumatology (ACR) criteria were included in this study. Joint pain and swelling were assessed. Pain, joint stiffness and disability were assessed by the Australian/Canadian OA hand index (AUSCAN). Radiographs of both hands were examined, and erosive disease was defined by at least one erosive interphalangeal joint. Synovial hypertrophy and power Doppler signal (PDS) were scored with ultrasound. Synovitis was graded on a scale of 0-3 and osteophytes were defined as cortical protrusions seen in two planes. Patients were examined at baseline and at the first, second and third year of follow up.

Results: Altogether, 97 patients (7 male) with symptomatic nodal HOA were included in this study and followed between April 2012 and January 2018. Out of these patients, 57 had erosive disease. The number of painful and clinically swollen joints $(p<0.05)$ was significantly higher in patients with erosive compared with non-erosive disease at baseline. The number of painful and clinically swollen joints fluctuate over the second and third year of follow up, but it still remains statistically higher $(p<0.01)$ at the third year of follow up in patients with erosive disease.

According to the AUSCAN, patients with erosive disease had more pain $(p<0.05)$ and stiffness $(p<0.01)$ at baseline. Pain and stiffness, but not function, worsened in patients with erosive compared with non-erosive disease after second year $(p<0.01)$. Pain $(p<0.01)$, stiffness $(p<0.05)$ and also function $(p<0.01)$ worsened in patients with erosive disease at the third year of follow up.

US-detected pathologies such as gray-scale synovitis $(p<0.001)$, intensity of PDS $(p<0.01)$ and number of osteophytes $(p<0.01)$ were significantly higher in patients with erosive disease at baseline. There were improvements in gray-scale synovitis total score and intensity of PDS in patients with non-erosive disease while patients with erosive disease worsened after the second and third year of follow up $(p<0.01)$. On the other hand, the progression of US-determined osteophyte formation was observed in both groups after the second year of follow up but were significantly higher in patients with erosive compared with non-erosive disease after the third year of follow up $(p<0.05)$.

Conclusions: The findings of this study show that pain and number of clinically swollen joints associated with US-detected synovial changes and osteophyte formation is more severe in patients with erosive HOA than in patients with non-erosive disease. In addition, osteophyte formation is more likely to progress independent of synovial inflammation.

Acknowledgements: This work was supported by the project (Ministry of Health Czech Republic) for consensual development of research organisation 023728. Disclosure of Interest: None declared DOI: 10.1136/annrheumdis-2018-eular.4887 